\title{
UNIDADES GEOTÉCNICAS DE SOLOS DE PORTO ALEGRE
}

\author{
Cezar Augusto Burkert BASTOS \\ Regina Davison DIAS
}

\section{RESUMO}

O artigo trata da caracterização dos solos do município de Porto Alegre para fins de engenharia, através da identificação e mapeamento de unidades geotécnicas, definidas com o auxílio de geologia e pedologia. São apresentados a metodologia dos trabalhos e os resultados obtidos, por meio de uma representação em pequena escala da Carta de Unidades Geotécnicas e de uma síntese das características físicas, morfológicas e mineralógicas verificadas para os materiais de cada uma das unidades de solos subtropicais com substrato de granitos e gnaisses.

\section{ABSTRACT}

The paper deals with the characterization of soils in Porto Alegre, for engineering purposes, by means of the identification and mapping of geotechnical units defined with the help of geology and pedology. The methodology and results of the work are presented by means of a reduced-scale map of geotechnical units and of a description of the physical, morphological and mineralogical characteristics of materials found in each of the units of subtropical soils, originated from granite and gneiss.

\section{INTRODUÇÃO}

O consistente conhecimento do meio físico com o qual interagimos é o caminho pelo qual o homem avançará ao progresso sem que se cometam agressões ao ambiente e à própria técnica.

Porto Alegre, não diferente de outros grandes centros urbanos, tem a maioria dos insucessos geotécnicos e do mau uso e ocupação dos solos, decorrentes do desconhecimento a respeito do solo, sua origem, gênese, ocorrência e propriedades.

Neste sentido, visando fornecer um instrumento básico ao planejamento de uso e ocupação do solo e anteprojetos em engenharia, foi elaborada uma Carta de Unidades Geotécnicas, estabelecendo uma compartimentação geológico-pedológica voltada a futuros trabalhos sobre temas geotécnicos específicos.

\section{MATERIAL E MÉTODOS}

\section{1 Área de estudo}

O município de Porto Alegre situa-se na porção leste do Estado de Rio Grande do Sul, às margens do lago denominado Rio Guaíba. Em $65 \%$ dos $500 \mathrm{~km}^{2}$ da cidade, o Escudo Cristalino Sul Rio-grandense se faz presente, com o relevo se constituindo em forte de morros e coxilhas, em contraste com a Planície Costeira Interna, composta pelas terras baixas (planícies aluviais, terraços fluviais e lacustres e banhados).

Destacam-se no município duas feições geológicas bastante distintas: o Embasamento Cristalino e sedimentos quaternários do Grupo Patos (segundo SHNEIDER et al., 1974). O primeiro é formado por um conjunto de corpos graníticos com denominações locais em meio a um intrincado complexo granítico-gnáissico. Os sedimentos quaternários envolvem formações pleistocênicas (paleodunas, depósitos fluviais, de fluxo de detritos e paleossolos coluviais) e holocênicas (sedimentos aluvionares recentes).

Segundo PROJETO RADAMBRASIL (1986), as classes pedológicas de solos encontradas em Porto Alegre são: Podzólicos Vermelho-Amarelados, Litólicos e Cambissolos, com substrato de granitos e gnaisses, e Planossolos, Gleis e Solos Aluviais, desde sedimentos quaternários.

2.2 Método de investigação das unidades geotécnicas

O método de trabalho segue as diretrizes apresentadas em DIAS (1989), sofrendo adequa- 
ções em face de peculiaridades da região e materiais estudados. Em linhas gerais, pode ser dividido em três etapas: estudo de escritório, investigação de campo e avaliação das características e propriedades geotécnicas dos materiais.

$\mathrm{Na}$ primeira etapa é realizada a coleta de dados, interpretação das informações e esboço cartográfico das unidades geotécnicas. O esboço das unidades geotécnicas foi executado com o cruzamento das informações de interesse geotécnico sobre a geologia e a pedologia. $\mathrm{O}$ objetivo é estimar zonas de ocorrência de solos com perfis de origem, características físicas e morfológicas e comportamento geotécnico semelhantes, que constituem as chamadas unidades geotécnicas. A geologia permite inferir as características do horizonte saprolítico (hor. C) e a pedologia, aquelas dos horizontes superficiais (hor. A e B). A topografia auxilia na definição dos limites entre unidades.

A nomenclatura adotada para as unidades geotécnicas foi inspirada nas indicações geológicas e pedológicas, dando idéia do perfil típico. É formada pela sigla do perfil pedológico predominante acompanhada por um índice que indica o substrato geológico.

Foram investigados, em taludes naturais ou escavações, perfis típicos das unidades geotécnicas estimadas em escritório. Foram descritos: seqüência, espessura e forma de transição dos horizontes, textura, consistência, minerais principais, resquícios estruturais da rocha de origem, macroestrutura e condição de drenagem dos materiais. Quando possível, afloramentos rochosos e matacões expostos foram investigados para melhor identificação do material de origem.

Desde amostras coletadas, realizaram-se ensaios para caracterização geotécnica clássica e estudo das propriedades de engenharia dos solos que compõem os perfis típicos.

A partir daí, completam-se os subsídios para a definição das unidades geotécnicas.

\section{RESULTADOS - UNIDADES GEOTÉCNICAS DE SOLOS PARA PORTO ALEGRE}

Com a aplicação do método de investigação exposto, foram mapeadas e caracterizadas as unidades geotécnicas de solos para o município de Porto Alegre. Foram detalhadas aquelas unidades de solos subtropicais originários dos granitos e gnaisses. São elas:

\section{-Litólicos de Granito - Rg}

$\operatorname{Rg}(\mathrm{g} . \mathrm{PG})$ - substrato Granito Ponta Grossa

$\operatorname{Rg}($ g.S $)$ - substrato Granito Santana

$\operatorname{Rg}(\mathrm{g} . \mathrm{I})$ - substrato Granito Independência

Rg(g.Cg) - substrato Granito Cantagalo;
- Litólicos do complexo granítico-gnáissico - Rg,gn;

- Podzólicos vermelho-amarelados c/ substrato granito - $\mathrm{PVg}$;

- Podzólicos vermelho-amarelados c/ substrato complexo granítico-gnáissico PVg,gn;

- Podzólicos vermelho-amarelados formados dos paleossolos ferralitizados do alterito Serra de Tapes - PVpf(AST).

As unidades geotécnicas de solos litólicos (Rg e Rg,gn) compõem-se de perfis pedologicamente classificados como litólicos, cambissolos e também podzólicos vermelho-amarelados muito pouco evoluídos onde o horizonte $\mathrm{B}$ muito raso tem pouca importância em termos geotécnicos. As unidades de solos podzólicos vermelho-amarelados ( $\mathrm{PVg}, \mathrm{PVg}$,gn e PVpf) agrupam os perfis pedológicos de mesmo nome.

Os solos hidromórficos (planossolos, gleis e solos aluviais), originados das formações sedimentares do Quaternário e aluviões recentes, constituem a unidade de nome Solos hidromórficos - HID.

A figura 1 ilustra uma reduzida representação da Carta de Unidades Geotécnicas de Porto Alegre, publicada em BASTOS (1991) na sua escala original (1:25.000).

Nos itens que seguem, as unidades são brevemente descritas quanto às principais características físicas, morfológicas e mineralógicas dos perfis. As propriedades de engenharia dos materiais necessitam abrangente abordagem e serão discutidas em outros trabalhos.

\subsection{Unidades PVg e Rg (g.PG) - substrato Granito Ponta Grossa}

Estas unidades apresentam perfis pouco desenvolvidos, com predominância dos horizontes saprolíticos.

O perfil típico de PVg apresenta um horizonte $\mathrm{B}$ de pequena espessura $(<2 \mathrm{~m})$, com vestígios de transporte, cor avermelhada e textura areno-argilosa, acusando a presença de grãos grosseiros (até $40 \%$ de areia grossa). O horizonte $\mathrm{C}$ saprolítico, comum às duas unidades, apresenta-se homogêneo, com tons amarelados e textura arenosa (até $75 \%$ de fração areia). A presença de matações é comum, sendo afloramentos de blocos observados no alto dos morros desta litologia. Tal horizonte já foi bastante explorado como material para aterros e pavimentação.

A mineralogia básica da litologia típica do Granito Ponta Grossa é: feldspato alcalino, quartzo, plagioclásio e biotita. O solo saprolítico apresenta fração grosseira composta por 
grãos de quartzo e feldspatos alcalinos em decomposição. A caulinita é o argilomineral predominante nos horizontes $\mathrm{B}$ e $\mathrm{C}$.

\subsection{Unidades PVg e Rg(g.Cg) - substrato} Granito Cantagalo
Estas unidades, de ocorrência menos significativa, não foram objeto de amostragem e estudo de propriedades em laboratório. Com a finalidade de reconhecer os materiais, foram investigados perfis localizados no Morro da Extrema (extremo sudeste da cidade).

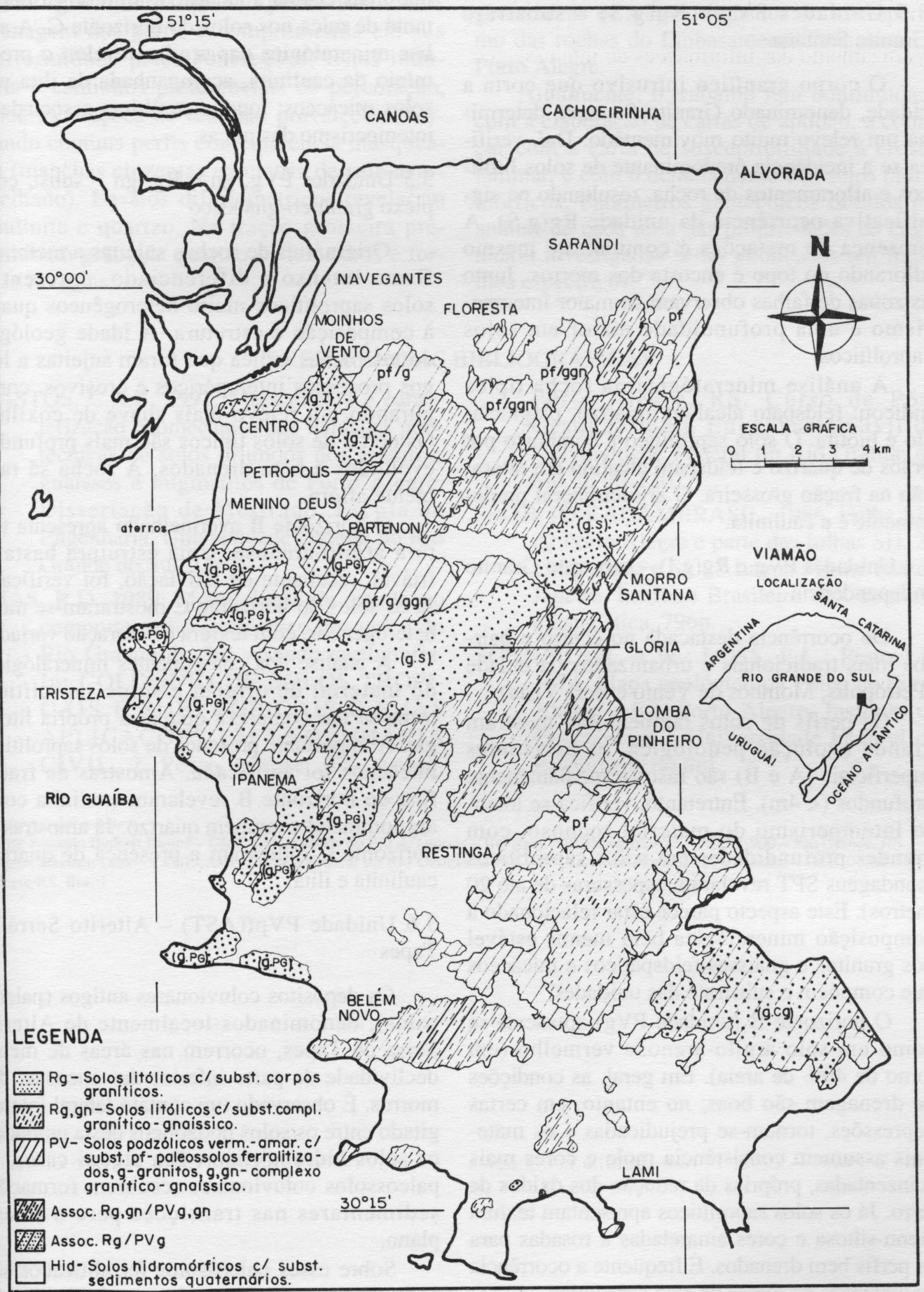

FIGURA 1 - Carta de Unidades Geotécnicas de Porto Alegre. 
Os perfis apresentam características físicomorfológicas bastante semelhantes àquelas relacionadas ao Granito Ponto Grossa. Os solos geralmente diferem na textura, pouco mais grosseira no horizonte C. Verificou-se o emprego do solo saprolítico em obras de pavimentação nas estradas interiores próximas.

\subsection{Unidades PVg e Rg(g.S) - substrato Granito Santana}

O corpo granítico intrusivo que corta a cidade, denominado Granito Santana, determina um relevo muito movimentado. Daí, verifica-se a incidência predominante de solos litólicos e afloramentos de rocha, resultando na significativa ocorrência da unidade $\operatorname{Rg}(\mathrm{g}$.S). A presença de matações é comum, até mesmo aflorando no topo e encosta dos morros. Junto às zonas de falhas observam-se maior intemperismo e uma profundidade maior em solos saprolíticos.

A análise mineralógica da rocha típica indicou: feldspato alcalino, quartzo, plagioclásio e biotita. O solo saprolítico é composto por grãos de quartzo e feldspato alcalino em alteração na fração grosseira. $\mathrm{O}$ argilomineral predominante é a caulinita.

\subsection{Unidades PVg e $\operatorname{Rg}(\mathrm{g} . \mathrm{I})$ - substrato Granito Independência}

De ocorrência destacada no centro e bairros mais tradicionais e urbanizados da cidade (Petrópolis, Moinhos de Vento e Bela Vista).

Os perfis de solos também não mostram grande evolução pedológica, os horizontes superficiais (A e B) são rasos a medianamente profundos $(<4 \mathrm{~m})$. Entretanto, verifica-se intenso intemperismo do material rochoso, com grandes profundidades em solos saprolíticos (sondagens SPT revelaram espessuras de até 20 metros). Este aspecto parece estar relacionado à composição mineralógica bem menos estável dos granitos e gnaisses feldspáticos e micáceos que compõem o substrato das unidades.

O horizonte B (unidade PVg) apresenta-se como um solo argilo-arenoso vermelho (em torno de $40 \%$ de areia). Em geral, as condições de drenagem são boas; no entanto, em certas depressões, tornam-se prejudicadas e os materiais assumem consistência mole e cores mais acinzentadas, próprias da redução dos óxidos de ferro. Já os solos saprolíticos apresentam textura areno-siltosa e cores amareladas a rosadas para os perfis bem drenados. É freqüente a ocorrência de matacões na massa de solo saprolítico.

A unidade geológica Granito Independência é composta desde granitos cinzas a gnaisses de acentuada xistosidade. Amostras coletadas de rocha granítica cinza revelaram como mineralogia básica: plagioclásio, quartzo, feldspato alcalino e mica biotita. Os solos saprolíticos apresentam significativo teor de silte e fração areia composta de feldspatos em decomposição e pouco quartzo. Entretanto, o que mais chama a atenção é a presença importante de mica nos solos do horizonte C. A análise mineralógica das argilas revelou o predomínio da caulinita, acompanhada da ilita para solos micáceos; logo, esta última associada ao intemperismo das micas.

3.5 Unidades PVg, gn e Rg, gn - subst. complexo granítico-gnáissico

Originárias de rochas sujeitas a metamorfismo intenso e diferenciado, apresentam solos saprolíticos muito heterogêneos quanto à composição e estrutura. A idade geológica destas rochas indica que foram sujeitas a longos processos intempéricos e erosivos, configurando um relevo mais suave de coxilhas. Os perfis de solos típicos são mais profundos, evoluídos e bem drenados. A rocha sã raramente aflora.

O horizonte B avermelhado apresenta textura argilo-arenosa. Uma estrutura bastante friável, resultante de lixiviação, foi verificada. Já os solos do horizonte $\mathrm{C}$ mostraram-se muito heterogêneos, com textura e coloração variadas.

A análise dos componentes mineralógicos do material de origem e solos saprolíticos torna-se tão complexa quanto a própria litologia. A importante presença de solos saprolíticos micáceos foi verificada. Amostras da fração fina do horizonte B revelaram caulinita como argilomineral e também quartzo. Já amostras do horizonte $\mathrm{C}$ indicaram a presença de quartzo, caulinita e ilita.

\subsection{Unidade PVpf(AST) - Alterito Serra de Tapes}

Os depósitos coluvionares antigos (paleossolos), denominados localmente de Alterito Serra de Tapes, ocorrem nas áreas de menor declividade da parte inferior das encostas dos morros. É observado um contato lateral interdigitado entre os solos podzólicos desta unidade e os solos hidromórficos. Em alguns casos, os paleossolos coluvionares recobrem formações sedimentares nas transições para o relevo plano.

Sobre esses paleossolos ferralitizados são formados os mais bem desenvolvidos perfis podzólicos vermelho-amarelados da região. Apresentam um horizonte B laterizado relativa- 
mente profundo. $\mathrm{O}$ transporte coluvionar é antigo e evidenciado pela presença de grãos grosseiros dispersos, "discordantes" com a textura mais argilosa do horizonte.

Forte cimentação por sesquióxidos foi observada. Agregações argilo-ferruginosas formam concreções que tornam estes solos muito rijos e duros quando pouco úmidos. A drenagem dos perfis é comprometida em sua uniformidade pelas concreções. Estas induzem a caminhos preferenciais de percolação, onde as reações de redução prevalecem, tornando comuns perfis com aparência mosqueada (manchas cinzentas na matriz de solo avermelhado). Ensaios difratométricos revelaram caulinita e quartzo. Na fração grosseira predominam grãos de quartzo de tamanhos e formas diversas.
O horizonte $\mathrm{C}$ corresponde à litologia recoberta por paleossolos.

\section{CONSIDERAÇÕES FINAIS}

O método de trabalho adotado mostrou-se eficiente, sendo alcançados como resultados o mapeamento e a caracterização das unidades geotécnicas de solos originados do intemperismo das rochas do Embasamento Cristalino em Porto Alegre.

Atualmente, o trabalho tem continuidade com a elaboração de cartas de aptidão, a começar com a carta de susceptibilidade à erosão laminar, e com o detalhamento dos solos hidromórficos. Parâmetros geotécnicos obtidos e a análise de cada uma das propriedades de engenharia investigadas serão publicados em trabalhos específicos.

\section{REFERÊNCIAS BIBLIOGRÁFICAS}

BASTOS, C.A.B. 1991. Mapeamento e caracterização geomecânica das unidades geotécnicas de solos oriundos dos granitos, gnaisses e migmatitos de Porto Alegre. Dissertação de Mestrado, Escola de Engenharia, Universidade Federal do Rio Grande do Sul, 156p.

DIAS, R.D. 1989. Metodologia de estudo do comportamento geotécnico dos solos do Rio Grande do Sul visando cartografia. In: COLÓQUIO DE SOLOS TROPICAIS E SUBTROPICAIS E SUAS APLICAÇÕES EM ENGENHARIA CIVIL, 2, Porto Alegre, RS. Anais.
Porto Alegre, RS. Curso de PósGraduação em Engenharia Civil da Universidade Federal do Rio Grande do Sul, p. 96-120.

PROJETO RADAMBRASIL. 1986. Folha SH. 22 Porto Alegre e parte das folhas SH. 21 Uruguaiana e SI. 22 Lagoa Mirim. Rio de Janeiro, Instituto Brasileiro de Geografia e Estatística, 796p.

SCHNEIDER, A.W.; LOSS, E.L.; Pinto J.F. 1974. Mapa geológico da Folha de Porto Alegre - RS. Porto Alegre, Instituto de Geociências - Universidade Federal do Rio Grande do Sul.

Cezar Augusto Burkert Bastos - DMC/Universidade do Rio de Grande - Rua Eng. Alfredo Huch, 475 - 96.201-900 - Rio Grande, RS. Regina Davison Dias - CPGEC/Universidade Federal do Rio Grande do Sul - Av. Osvaldo Aranha, 99 - $3^{\circ}$ andar - $90.210-000$ - Porto Alegre/RS. Brasil 